American Journal of Applied Sciences 8 (12): 1374-1377, 2011

ISSN 1546-9239

(C) 2011 Science Publications

\title{
Design Analysis of An Electromagnetic Band Gap Microstrip Antenna
}

\author{
${ }^{1,2}$ M.S. Alam, ${ }^{2}$ M.T. Islam and ${ }^{1,2}$ N. Misran \\ ${ }^{1}$ Department of Electical, Electronic and Systems Engineering, \\ ${ }^{2}$ Institute of Space Science (ANGKASA), \\ Faculty of Engineering and Built Environment, \\ University Kebangsaan Malaysia, 43600 Bangi, Selangor D E, Malaysia
}

\begin{abstract}
Problem statemet: Wideband compact antenna is highly demandable due to the dynamic development in the wireless technology. Approach: A simple, compact EBG microstrip antenna is proposed in this study that covers a wideband of $250 \mathrm{GHz}$ and the design is conformal with the $2.45 \mathrm{GHz}$ ISM band (WLAN, IEEE $802.11 \mathrm{~b}$ and g)/Bluetooth/RFID applications. Results: A $6 \times 6$ array of square unit cell formed the EBG structure which is incorporated with the radiating patch to enhance the antenna performances. This design achieved an impedance bandwidth of $10.14 \%(2.34-2.59 \mathrm{GHz})$ at $-10 \mathrm{~dB}$ return loss and VSWR $\leq 2$. Simulated radiation pattern is almost omnideirectional. Conclusion/Recommendations: The simulated results prove the compatibility of the EBG antenna with the $2.45 \mathrm{GHz}$ ISM band applications. Further enhancement of the antenna performance with improved design is under consideration.
\end{abstract}

Key words: Wireless technology, electromagnetic modes, periodical structure, wide bandwidth, wireless communications, space programs, short range radio

\section{INTRODUCTION}

Recent advances in wireless communications, radar, satellite and space programs have introduced tremendous demands in the antenna technology (Mobashsher et al., 2010; Shakib et al., 2010a; 2010b; Azim et al., 2011; Islam et al., 2009a; 2010b). Among the various type of antenna, microstrip antennas are of special interest because of their light weight, low profile, compactness and compatibility with integrated circuits, though they suffer from some drawbacks e.g., narrow bandwidth, low gain and excitation of surface waves (Garg et al., 2001; Azim et al., 2010). To overcome these limitations, new methods are still being explored and the interesting features of Electromagnetic Band Gap (EBG) materials have attracted the antenna researchers.

Usually, the Electromagnetic Band Gap (EBG) materials are periodical structures composed of metallic or dielectric elements. Addition of defects into the periodical structure, exhibits the ability to reject the propagation of the electromagnetic waves whose frequency is included within their frequency band gap and to open localized electromagnetic modes inside the forbidden frequency band (Yablonovitch, 1987). EBG always referred as high impedance surface that increase antenna surface efficiency by suppressing the unwanted surface wave current. Suppression of surface waves excitation helps to improve antenna's performance such as reduces backward radiation and increase antenna gain (Gonzalo et al., 1999).

In the recent past, the communication devices had been emerged rapidly (Alam et al., 2009; Azim et al., 2011). To cope with this fast development in wireless technology, miniaturization of antenna with wideband and good radiation characteristics is very much desirable (Faruque et al., 2010; Islam et al., 2009b; 2010a). In this regard, design of an antenna with reduced size while maintaining good performance in the Industrial Scientific and Medical (ISM) band of 2.4-2.5 GHz is in our concentration. This frequency allocation complies with the IEEE 802.11b Wireless Local Area Network (WLAN), Bluetooth and RF Identification Devices (RFID) applications. Bluetooth is a Wireless Personal Area Networking (WPAN) technology which is well suited for short range radio links between portable devices. Similarly, WLAN is efficient for medium range wireless communication environment where as RFID is widely used in tagging, tracking, monitoring and detection of objects (Ali et al., 2002; Finkenzeller, 2003). Different type of microstrip antenna satisfies the dualband operation for the ISM band 2.45/5.8 GHz have been

Corresponding Author: M.T. Islam, Institute of Space Science (ANGKASA), Faculty of Engineering and Built Environment, University Kebangsaan Malaysia, 43600 Bangi, Selangor D E, Malaysia 
investigated and published with good results. But still there are many applications in wireless communication greatly demand the operation of single-band antenna (Mobashsher et al., 2010; Chen et al., 2009; Zhang et al., 2009; Pan et al., 2005).

In this study, a simple and compact EBG microstrip antenna is proposed that is conformal with the short range and medium range wireless network operation. It covers the frequency band of 2.34-2.59 $\mathrm{GHz}$ and this design could be adopted for single band WLAN/PAN applications. Some parametric studies have been realized on the EBG structure and the radiating patch to achieve a high performance antenna. A rectangular patch over an array of EBG unit cell is designed and optimized for better performance. Considerable improvement in terms of bandwidth and radiation pattern is obtained which confirmed the suitability of the compact design for ISM band (WLAN, IEEE $802.11 \mathrm{~b} / \mathrm{g}$ )/Bluetooth/ RFID applications.

Antenna design geometry: The schematic diagram of the coaxial probe fed EBG antenna with a finite ground plane is shown in Fig. 1. It consists of two layers and the radiating element is printed on the upper surface of the top layer. The bottom layer carries an array of square metallic patch printed on the dielectric substrate. The gray parts represent the metallic periodic structure and the black part is the radiator. This structure has a compact dimension of $34.5 \times 34.5 \mathrm{~mm}$. From the theoretical approach, the dimensions of a microstrip patch radiator can be modeled by using the following formulas (Bahl and Bhartia, 1980). For an efficient radiator, the practical width that leads to good radiation efficiencies is Eq. 1a:

$$
\mathrm{W}=\frac{\mathrm{c}}{2 \mathrm{f}_{0}} \sqrt{\frac{\varepsilon_{\mathrm{r}}+1}{2}}
$$

Where:

$\mathrm{c}=$ The free space speed of light

$\varepsilon_{\mathrm{r}}=$ The relative permittivity of dielectric substrate

The microstrip patch lies between air and dielectric material and thus, the effective dielectric constant can be found by Eq. $1 \mathrm{~b}$ :

$$
\varepsilon_{\mathrm{e}}=\frac{\varepsilon_{\mathrm{r}}+1}{2}+\frac{\varepsilon_{\mathrm{r}}-1}{2}\left[1+\frac{12 \mathrm{~h}}{\mathrm{~W}}\right]^{-1 / 2}
$$

where, $\mathrm{h}$ is the thickness of the substrate. The actual length of the patch can be determined by Eq. 1c:

$$
\mathrm{L}=\frac{\mathrm{c}}{2 \mathrm{f}_{0} \sqrt{\varepsilon_{\mathrm{e}}}}-2 \Delta \mathrm{l}
$$

where, $\Delta \mathrm{I}$ is the extension in $\mathrm{L}$ and is given by Eq. $1 \mathrm{~d}$ :

$$
\Delta \mathrm{l}=0.412 \mathrm{~h} \frac{\left(\varepsilon_{\mathrm{r}}+0.3\right)\left(\frac{\mathrm{W}}{\mathrm{h}}+0.264\right)}{\left(\varepsilon_{\mathrm{e}}-0.258\right)\left(\frac{\mathrm{W}}{\mathrm{h}}+0.8\right)}
$$

The EBG structure has $6 \times 6$ unit cells and an overall dimension of $32.5 \times 32.5 \mathrm{~mm}$, printed on a very inexpensive $1.6 \mathrm{~mm}$ thick $\left(\mathrm{h}_{1}\right) \mathrm{FR}-4$ dielectric substrate with relative permittivity $\left(\varepsilon_{\mathrm{r} 1}\right)$ of 4.4 and loss tangent $(\delta)$ of 0.02 . The antenna designed on a finite ground plane with a dimension of $34.5 \times 34.5 \mathrm{~mm}$. The length $\left(\mathrm{L}_{\mathrm{u}}=\mathrm{W}_{\mathrm{u}}\right)$ of the square EBG metallic patch is $5 \mathrm{~mm}$ and their spacing with adjacent patches is $0.5 \mathrm{~mm}$. Thus the period of the lattice is $5.5 \mathrm{~mm}$.

A rectangular radiating patch of $\left(\mathrm{L}_{\mathrm{p}}\right)$ 13.6× $\left(\mathrm{W}_{\mathrm{p}}\right)$ $14.5 \mathrm{~mm}$ with an extended microstrip line of $2.5 \mathrm{~mm}$ width $\left(\mathrm{W}_{\mathrm{m}}\right)$ and $3.1718 \mathrm{~mm}$ length $\left(\mathrm{L}_{\mathrm{m}}\right)$ is printed on the top layer. An air-filled substrate of thickness $\left(\mathrm{h}_{2}\right)$ $6.4 \mathrm{~mm}$ is sandwiched between the rectangular patch and the EBG structure. The patch is directly fed by a coaxial probe of radius $0.5 \mathrm{~mm}$ on the microstrip line and the feeding position is at the midpoint along $\mathrm{X}$-axis and $8.5 \mathrm{~mm}$ away along the $\mathrm{Y}$-axis. (b)
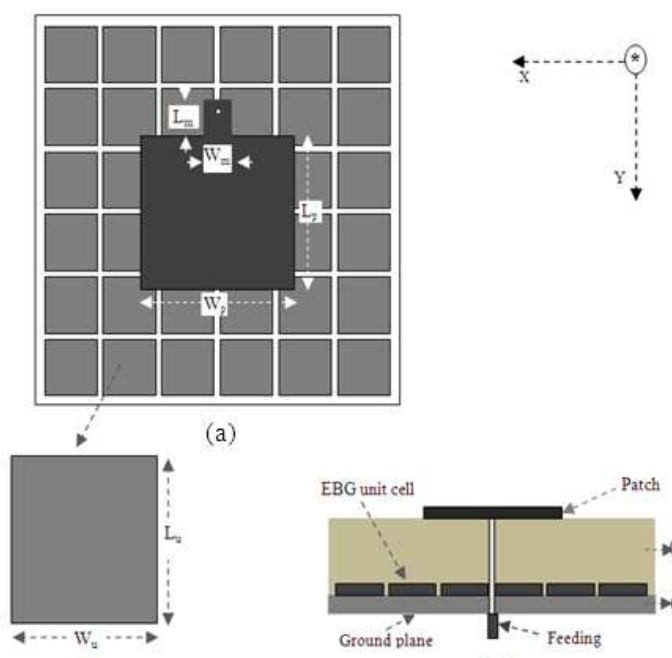

Fig. 1: Geometry of the proposed EBG antenna (a) top view (b) EBG unit cell (c) side view 


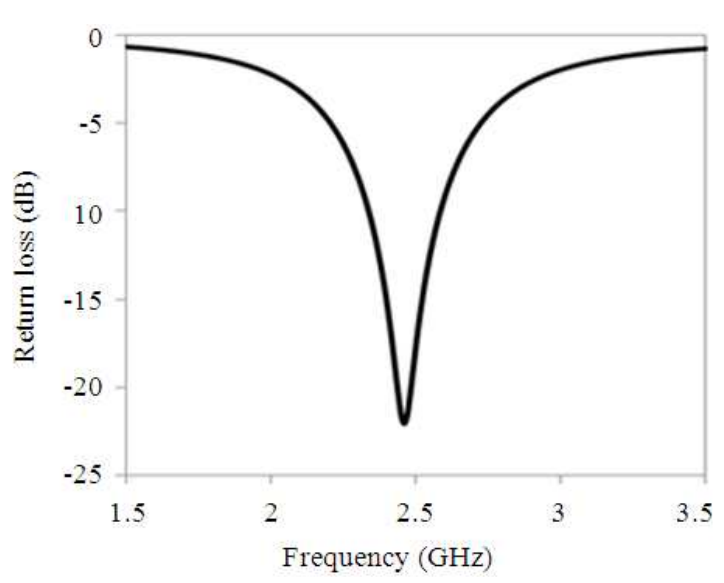

Fig. 2: Return loss of the proposed EBG antenna

\section{MATERIALS AND METHODS}

Finite Element Method (FEM) based full wave eletromagnetic simulator Ansoft's HFSS v.10 is utilized to design and study the proposed EBG antenna performances. This design is aimed to be a simple construction with smaller size. First, the EBG structure is designed to have a wide band gap and then the rectangular radiating patch is optimized to meet the $2.45 \mathrm{GHz}$ ISM band WLAN applications reqiurement. The antenna is directly fed by a coaxial probe and some parametric studies are performed to obtain the feeding position to avoid impedance mismatch.

\section{RESULTS}

The study of return loss and radiation characteristics is the vital for the microstrip patch antenna design. Figure 2 shows the simulated return loss behavior of the EBG antenna. For return loss $<-10 \mathrm{~dB}$, the proposed antenna achieved an impedance bandwidth of $250 \mathrm{MHz}(2.34-2.59 \mathrm{GHz})$. The return loss curve reached down to $-22.15 \mathrm{~dB}$ at the resonant frequency of $2.46 \mathrm{GHz}$. The wideband of the design can also be seen from Fig. 3, at VSWR $\leq 2$ is (2.34-2.59) GHz.

The simulated radiation patterns for the E-plane and $\mathrm{H}$-plane of the proposed EBG antenna at frequency $2.46 \mathrm{GHz}$ is shown in Fig. $4 \mathrm{a}$ and b, respectively. The pure black and dotted curves in the figures respectively represent the co-polarization and the cross-polarization characteristics.

In the E-plane the pattern is likely to be directional and the co-polar component is higher than the crosspolar component. The radiation in the H-plane is almost omni-directional and the cross-polar component is very lower than the other one.

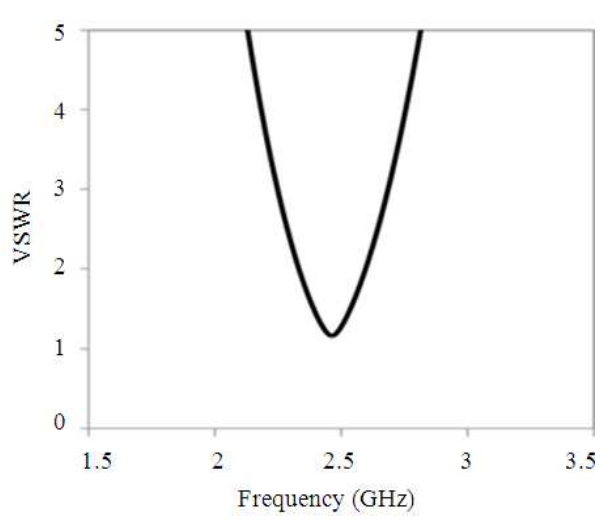

Fig. 3: VSWR of the EBG antenna

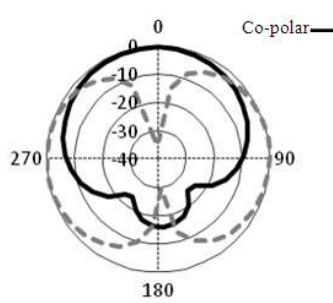

(a)

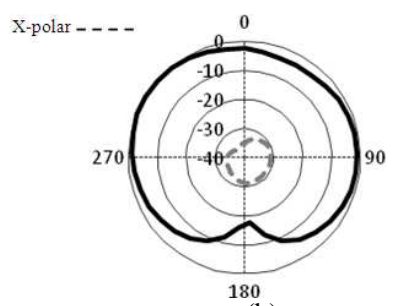

(b)
Fig. 4: A E-plane b H-plane Radiation patterns for the proposed EBG antenna at $2.46 \mathrm{GHz}$

\section{DISCUSSION}

Inspite of the compactness, the proposed antenna achieved a wideband with a resonant frequency of 2.46 GHz. As depicted in the Fig. 2 and 3 in the result section, the operating frequency band $(2.34-2.59 \mathrm{GHz})$ obtained by the EBG microstrip antenna makes it appropriate for (2.4-2.5) GHz ISM band WLAN applications. From the $\mathrm{E}$ and $\mathrm{H}$-plane radiation curves it is observed that, throughout the bandwidth the designed EBG antenna achieved almost omni-directional radiation pattern.

\section{CONCLUSION}

The design and simulated characteristics of a compact EBG rectangular patch antenna is presented here for wireless short range and medium range operation. With the optimized antenna configuration, the proposed antenna offers an impedance bandwidth of $10.14 \%(2.34-2.59 \mathrm{GHz})$, which is sufficient enough for $2.45 \mathrm{GHz}$ ISM band (WLAN, IEEE $802.11 \mathrm{~b}$ and g)/ Bluetooth/RFID applications. The radiation patterns are almost omni-directional and stable throughout the bandwidth. Utilization of the EBG structure shows improvement of the antenna performance significantly. 
In terms of return loss and radiation pattern behavior, the proposed antenna with smaller size, exhibits its suitability with the aforementioned wireless communication technology.

\section{REFERENCES}

Alam, A.H.M.Z., M.R. Islam, S. Khan and M.M. Rashid, 2009. Microelectrical mechanical systems switch for designing multi-band antenna. J. Comput. Sci., 5: 479-486. DOI: 10.3844/jcssp.2009.479.486

Ali, M., R.A. Sadler and G.J. Hayes, 2002. A uniquely packaged internal inverted-f antenna for bluetooth or wireless LAN Applications. IEEE Antenna Wireless Propagation Lett., 1: 1. DOI: 10.1109/LAWP.2002.802574

Azim, R., M.S. Alam, N. Misran, A.T. Mobashsher and M.T. Islam, 2011. Compact planar antenna with dual band-notched characteristics for UWB applications. Proceedings of the IEEE International Conference on Space Science and Communication (IconSpace), Jul. 12-13, IEEE Xplore Press, Penang, pp: 269-272. DOI: 10.1109/IConSpace.2011.6015898

Azim, R., M.T. Islam and N. Misran, 2010. A planar monopole antenna for UWB applications. International Review Electrical En., 5: 1848-1852.

Bahl, I.J. and P. Bhartia, 1980. Microstrip Antennas. 2nd Edn., Artech House, Boston, London, ISBN: 9780890060988, pp: 348.

Chen, H.M., Y.K. Wang, Y.F. Lin, S.C. Lin and S.C. Pan, 2009. A compact dual-band dielectric resonator antenna using a parasitic slot. IEEE Antennas Wireless Propagation Lett., 8: 173-176. DOI: 10.1109/LAWP.2008.2001119

Faruque, M.R.I., M.T. Islam and N. Misran, 2010. Evaluation of Specific Absorption Rate (SAR) Reduction for PIFA Antenna using Metamaterials Frequenz, 64: 144-149. DOI: 10.1515/FREQ.2010.64.7-8.144

Finkenzeller, K., 2003. RFID Handbook: Fundamentals and Applications in Contactless Smart Cards and Identification. 2nd Edn., John Wiley and Sons, Chichester, West Sussex, ISBN: 9780470844021, pp: 427.

Garg, R., 2001. Microstrip Antenna Design Handbook. 1st Edn., Artech House, Boston, London, ISBN: 9780890065136, pp: 845.
Gonzalo, R., P.D. Maage and M. Sorolla, 1999. Enhanced patch antenna performance by suppressing surface waves using photonic-bandgap substrates. IEEE Trans. Microwave Theory Tech. 3: 11. DOI: 10.1109/22.798009

Islam, M.T., A.T. Mobashsher and N. Misran, 2010a. A novel feeding technique for a dual-band microstrip patch antenna. IEICE Trans. Commun., 9: 24552457. DOI: 10.1587/transcom.E93.B.2455

Islam, M.T., A.T. Mobashsher and N. Misran, $2010 \mathrm{~b}$. Coplanar waveguide fed printed antenna with compact size for broadband wireless applications. J. Infrared, Millimeter Terahertz Waves, 31: 14271437. DOI: 10.1007/s10762-010-9728-7

Islam, M.T., M. Moniruzzaman, N. Misran and M.N. Shakib, 2009b. Curve fitting based particle swarm optimization for UWB Patch Antenna. J. Electromagnetic Waves Appli., 23: 2421-2432. DOI: 10.1163/156939309790416008

Islam, M.T., M.N. Shakib and N. Misran, 2009a. Multislotted microstrip patch antenna for wireless communication. Progress Electromagnetics Rese. Lett., 10: 11-18. DOI: 10.2528/PIERL09060704

Mobashsher, A.T., M.T. Islam and N. Misran, 2010. A novel high-gain dual-band antenna for RFID reader applications. IEEE Antennas Wireless Propagation Lett., 9: 653-656. 10.1109/LAWP.2010.2055818

Pan, C.Y., C.H. Huang and T.S. Horng, 2005. A new printed g-shaped monopole antenna for dual-band WLAN applications, microwave opt. Tech. Lett., 45: 295-297. DOI: 10.1002/mop. 20800

Shakib, M.N., M.T. Islam and N. Misran, 2010a. Highgain w-shaped microstrip patch antenna. IEICE Electronics Express, 7: 1546-1551. DOI: 10.1587/elex.7.1546

Shakib, M.N., M.T. Islam and N. Misran, 2010b. Stacked patch antenna with folded patch feed for ultra-wideband application. IET Microwaves Antennas Propagation, 4: 1456-1461. DOI: 10.1049/iet-map.2009.0257

Yablonovitch, E., 1987. Inhibited spontaneous emission in solid state physics and electronics. Phys. Rev. Lett., 58: 2059-2062. DOI: 10.1103/PhysRevLett.58.2059

Zhang, J., X.M. Zhang, J.S. Liu, Q.F. Wu, T. Ying and H. Jin, 2009. Dual-band Bidirectional High gain Antenna for WLAN 2.4/5.8 GHz applications. Electronics Lett., 45: 6-7. DOI: 10.1049/el:20092617 